\title{
LA MODERNIDAD DE SIGÜENZA Y GÓNGORA
}

Rafael Moreno

Facultad de Fllosofía y Letras Universidad Nacional autónoma de México

La modernidad es una categoría concebida para calificar, valorar y reflexionar - todo a la vez- sobre el pensamiento hispanoamericano, o pensamiento de lengua española, moderno, en contraposición al antiguo o tradicional. La categoría no está desnuda de prosapia. José Gaos le da connotación propia y la aplica a la comprensión de la filosofía hispanoamericana de los siglos xviI y xviI, la cual se define por un eclecticismo peculiar. En sus manos la modernidad viene a ser una categoría filosófica que proporciona la explicación, nada menos, de la historia mental, moderna, recorrida por los pueblos de habla española.

Surge la modernidad de la tendencia a occidentalizarse, o modernizarse, opuesta a la tendencia a la conservación y a la tradición. La historia aparece como un forcejeo entre modernizadores y tradicionalistas, entre lo nuevo y lo anticuado, entre la reforma y la posesión estática de la verdad. Tales son las apariencias. El fondo es el cambio de la cultura medieval por la cultura moderna. Moderno no corresponde a Edad Moderna, pues mientras ésta se refiere a los sucesos posteriores a la Edad Media, lo moderno designa de suyo tener o cultivar la ciencia, la filosofía, la historia, la economía, la educación a que da origen la crisis renacentista. El concepto moderno implica hechos de modernidad que deben presentarse, en cada caso histórico, con abundancia y con fuerza demostrativa. Por donde se ve que la modernidad no sólo explica los siglos xviI y xvIII, sino también proporciona el trasfondo histórico sin el cual no puede entenderse el liberalismo del siglo xIx.

La modernidad es una categoría que se formula especulativamente, pero cuyas características se definen a posteriori, por los mismos hechos culturales, desde el punto de vista en que una época o una personalidad los estiman y ordenan. La escuela de Gaos - Justino Fernández, Edmundo O’Gorman, Leopoldo Zea, Vera Yamuni, Bernabé Navarro, Luis Villoro, Fernando Salmerón, Raúl Cardiel Reyes, Elsa Frost, Rafael Moreno - ha mostrado la fecundidad de la categoria, indicando el contenido concreto que le asignan las figuras centrales y los periodos histó- 
ricos. En este sentido cabe ahora caracterizar la modernidad de don Carlos de Sigüenza y Góngora. Interpretarlo a través de la categorfa de modernidad será un acercamiento a nosotros para conocer una circunstancia importante de nuestra historia. Pues el matemático-astrólogofilósofo-historiador-literato barroco (1645-1700) inaugura la modernidad, junto con su amiga, la monja jerónima de nombre Sor Juana. Sigüenza, en efecto, no sólo aporta datos de una ciencia distinta a la anterior y cultiva una nueva; también prohijó un pensamiento que descansa en una concepción moderna y expone y defiende una ciencia moderna. Este erudito barroco, por otra parte, ya viene siendo reconocido, desde muy atrás en la historia, como un pensador que no es periférico a la cultura mexicana, sino sustantivo como pocos. A Sigüenza Marcelino Menéndez y Pelayo lo considera honra general de la Nueva España. "La aparición de tal hombre en los días de Carlos II basta para honrar a una universidad y a un pafs." Se trata, pues, de una personalidad adecuada para conocernos y para precisar cuestiones que decidieron el curso de los días mexicanos.

La operación de análisis puede cumplirse en el libro de Laura Benítez Grobet, La idea de historia en Carlos de Sigüenza y Góngora (UNAM, México, 1982). La investigación sobre la modernidad está hecha. La autora estudia a don Carlos desde el ángulo propio de la historia de las ideas; lee y comprende, interpreta y construye su pensamiento, tanto de los escritos científicos como de los históricos y literarios, y lo presenta a la luz de la historia filosófica de México. La descripción de la obra de Sigüenza viene a ser lo mismo que probar, por primera vez en una obra entera, qué lugar ocupa en nuestra historia de la filosofía. Alcanza tal logro a través de la aclaración y definición del concepto modernidad. El tema que domina, el propósito que da sentido a la obra, es de mucho momento: cómo y por qué Sigüenza es un pensador moderno, dónde están las ideas modernas y cuáles son las significaciones de éstas. El cultivo de la ciencia, de la razón, del método, de la crítica, sea en asuntos científicos, sea en temas históricos, arroja el hecho indubitable del carácter moderno exhibido por Sigüenza.

Laura Benítez deja en claro el cambio de mentalidad que se opera gracias a la presencia histórica del erudito barroco. La Nueva España, adormilada en la tradición y en la ciencia escolástica, inserta en la clausura espiritual ante el conocimiento europeo, sale de su letargo de manera definitiva por obra y gracia de Sigüenza. Con este sabio, erudito, matemático, historiador, astrólogo y astrónomo, cambia el mundo colonial del medioevo a la época moderna. Así lo indican sus obras científicofilosóficas, como la Libra astronómica y filosófica y el Manifiesto filosófico contra los cometas, lo mismo que sus obras históricas, entre las 
que cabe citar Los infortunios de Alonso Ramirez, el Mercurio Volante, la Piedad Heroyca, el Theatro de virtudes. No están exentas de tal sentido las obras literarias que bien representa el Triunpho Parthénico.

No hay ninguna duda sobre la pertenencia del sabio mexicano a los tiempos modernos. La cuestión, sin embargo, reside en señalar el grado de ser moderno. Lo que equivale, de paso, a entender su pensamiento. En páginas decisivas viene una explicación a posteriori del concepto, inducida del análisis de los datos que aporta el mismo Sigüenza. El concepto de moderno, nos dice, se sustenta en un criterio, en una perspectiva histórica desde la cual se expone tal criterio y en los hechos que vuelven racionales criterio y perspectiva. A los hechos está dedicado el libro. Según el criterio se entiende por moderno, a propósito de las ideas, el rechazo de Sigüenza a lo tradicional, o sea, su oposición a los valores tradicionales. El término conlleva la crisis producida por la ruptura e indica una escisión del mundo tradicional, como un lento proceso de cambio "plagado de contradicciones, en el que las nuevas teorias se van consolidando paulatinamente". La perspectiva es el ángulo o el campo a partir del cual se plantea la modernidad: la concepción científica y económica, la historia, el nacionalismo, el criollismo. Llama "dialéctica" a la perspectiva porque las crisis de las ideas tradicionales y la aparición de las nuevas ideas son un "proceso de cambio", en el cual hay un desarrollo de las contradicciones y una superación de las mismas.

Lo cual vuelve comprensible a Sigüenza. En efecto, quedan entendidas las contradicciones: que haya astrología y astronomía, que se recurra a las autoridades y a la razón, que junto a las pruebas de matemática certidumbre surjan las provenientes de la imaginación, que sea válida la explicación basada en la naturaleza y la explicación elaborada por la metafísica, que coexistan los hechos objetivos de la historia y el providencialismo y los milagros, que el lenguaje sea mayormente escolástico y los temas pertenezcan a los días modernos. Las contradicciones son el síntoma de estar a la altura de los tiempos. Pero todavía la autora avanza más gracias a su teoría de lo moderño. En seguimiento de José Gaos se ha tenido a Sigüenza por un autor de transición, que al mismo tiempo sostiene afirmaciones antiguas y nuevas. Laura Benítez opina que no es aưtor de transición, aunque exprese el tránsito a los tiempos modernos. Más bien "es un autor moderno porque la modernidad misma es transición". Don Carlos resume en sí mismo diversas tendencias. Su carácter bipolar lo hace moderno. No sólo admite las contradicciones científicas, filosóficas, históricas como características suyas, sino en virtud de ellas adquiere el carácter de hijo del siglo xvir, "absolutamente acorde con su tiempo y exponente singular de la cultura novohispana de vanguardia". El verdadero avance en la historia de las ideas está a la vista: a Si- 
güenza lo convierten en moderno sus notas de modernidad y no primariamente las noticias modernas. Donde ya puede indicarse la distinción de moderno y modernidad.

En Sigüenza la modernidad no está en citar a Gassendi, Copérnico, Galileo, o en ser discípulo a trasmano de Descartes. Está precisamente en construir una cultura nueva, no construida igual hasta entonces, formada por tesis que valen científica y socialmente, dentro de la ciencia, la historia y la religión. No crea ni una ciencia ni unas teorías científicas: sólo da las bases para una nueva visión del mundo; ofrece al país, a su patria, principios y métodos modernos; descubre su propia nación y ejerce la orientación racionalista del saber.

Veamos, con enunciados, cómo transforma la mentalidad novohispana. Antes que nada todos los actos del sabio erudito se dirigen a buscar las "luces apacibles de la verdad", cuando sus compatriotas practicaban el apego a doctrinas acostumbradas. Predica en sus abundantes obras el desengaño de errores imbuidos. No acepta los "oráculos o dogmas" y legitima la libertad de disentir. Su actitud crítica lo conduce a evitar la prevención y los prejuicios, al mismo tiempo que exige fundamentos y solidez para el conocimiento. Su camino es el método que guía hacia la verdad, eliminando los prejuicios a partir de la duda, separando lo verdadero de lo falso, fijando la evidencia como criterio de verdad. El método sirve también para averiguar la verdad "sin divertirse" y sin caer en paralogismos, no menos que para adquirir verdades provechosas o útiles. Ya prevé la separación entre la verdad religiosa y la verdad cientificica, lo que será la gran tarea de Alzate en la segunda mitad del siglo Xvir novohispano. El hombre es para él un ser activo con una gran posibilidad de desarrollo y de conocimiento. Y no jura por la autoridad de ninguno, sino examina todas las doctrinas y les pide congruencia a la moderna. Todas estas notas son formas de practicar la inteligencia; constituyen una cultura nueva; cambian el mundo tradicional por el moderno.

Particularmente en ciencia introduce, con apoyo en su maestro Diego Rodríguez, una revolución al proponer y aplicar el cálculo y la observación astronómicos, así como al manejar instrumentos y poner en uso la matemática. Postula la verificación de los principios y va de la hipótesis a la comprobación. En astronomía emplea la demostración empirica y la racional, una resultado de la observación y otra hija de la comprobación por el cálculo acertado. Establece ya el principio de causalidad universal. Basta la simple enumeración para advertir que Sigüenza cambia la mentalidad escolástica por la moderna.

Aquí está la modernidad peculiar de la segunda mitad del siglo xvir. La expresa, como un dechado, el autor barroco. No consiste en sostener 
tesis modernas. Eruditamente a cada tesis moderna puede oponérsele una doctrina o una actitud tradicional y hasta medieval. Un cotejo cuantitativo colocaría cualquiera de las dos tendencias en la cumbre. La modernidad significa tres operaciones: una es la incorporación de la Nueva España a la ciencia normal europea, de manera que los novohispanos conozcan lo que saben los curopcos; otra es la inserción de la propia realidad y mundo en la ciencia europea, de manera que se aplique la ciencia al mundo inmediato, como viene a ser el caso de Sigüenza que explica a los novohispanos la índole de los cometas y, a la vez, los despoja de los funestos signos que les atribuían. Una tercera viene a ser la elevación del mundo novohispano a significación universal, ya convertido en parte de la civilización y del mundo europeo. Todo esto significa la modernidad que origina en la Nueva España la ciencia moderna.

Lo moderno aparece igualmente en la historia, donde don Carlos practica una historia-ciencia. A ella traslada sus concepciones científicas y además indica características propias de lo histórico, como la utilización de las fuentes, la revisión y autentificación de las mismas, la utilidad de la historia para descubrir el error científico, la crítica que tiene valor en el descubrimiento de los errores y de las afirmaciones infundadas, o de los argumentos endebles y falsos. Remite a los archivos para seleccionar las fuentes. Busca el conocimiento cierto, alejado de la fantasía y de los entes de razón. En todo lo cual se adelanta nada menos que al benedictino Feijoo, que vino a modernizar el pensamiento de Iengua española en la primera mitad del siglo xvirr. Modernidad así mismo practica Sigüenza en su concepción autónoma del hombre, si bien se trata de un hombre selecto que hace la historia y cuya acción, providencialmente planificada, ejerce una influencia decisiva en el curso del acontecer. Además, como si fuera renacentista, pone por explicación de los hechos la dualidad de los contrarios; incluso, en algunos casos, une la necesidad con la azarosa fortuna. Cabe mencionar que la historia tiene en el sabio mexicano el doble carácter de memoración y ejemplaridad. En fin, la historia está ligada a la exaltación de los valores humanos propios de su siglo, de su cultura y de su ideología. De modo que la historia viene a ser "un teatro de virtudes que sirven para normar la acción". El conjunto presenta las condiciones bajo las cuales comienza a practicarse la cultura social en Ios tiempos nuevos de la Colonia.

Éstos son los elementos de la modernidad que lleva a cabo el erudito barroco. La ciencia aplicada al país transforma a éste. De ahí que el país obtenga, desde la ciencia y la historia, la condición de nación y que el criollo agrande la conciencia de su singularidad respecto de España. No en balde Laura Benítez afirma: "el criollo es un producto de la Edad Moderna", lo que completa cuando señala el pasado indígena como 
fundamento del criollismo. Ciertamente, bajo el influjo del mundo moderno, el criollo Sigüenza se mira singular frente al español por tener una raíz indígena que es gloriosa. Su alma aparece dual: española, pero española con un pasado propio, el pasado indígena. La integración de dos raices resulta todavía precaria; ya existe, sin embargo, la identidad que llegará hasta las puertas de la guerra de independencia. Del anhelo general de los criollos por mostrar una patria, una nación que les pertenezca de alguna manera, transita conscientemente a sobrepesar la singularidad. Proporcionan la visión los tiempos modernos, los cuales descubren las realidades distintas, concretas, individuales. A lo mismo conduce el hábito de la observación, de la experimentación y de la medición, pues son operaciones sobre individuos.

Por otra parte, en su Theatro de virtudes Sigüenza ejemplifica con los monarcas antiguos mexicanos las cualidades de un gobernante. Gracias a Sigüenza el Arco Triunfal, erigido por la ciudad de México en honor del nuevo virrey, queda hermoseado con las efigies indigenas. El pasado propio reemplaza al otro pasado también propio, pero venido de lejos. A la cultura antigua grecolatina la tiene por impropia, esto es, no reveladora de virtudes; también la juzga mítica, de seguro no por razones morales, sino porque no atiende a la verdad objetiva. Su dedicación a la verdad, en todas las manifestaciones de ésta, no podía sufrir el desengaño mitológico frente a las virtudes probadas en hechos, como aseguraban tantos documentos que sobre las antigüedades mexicanas guardaba amorosamente. Los datos, pues, y los testimonios, vistos con ojos modernos, dan al criollismo una base en el pasado indígena valioso y ejemplar. La modernidad, cierto, no hace al criollo; empero, lo acompaña y da sentido a sus afirmaciones.

Sigüenza participa en el levantamiento de una criolla nación, según reitera la autora. Es criollo no sólo por haber nacido en la América Septentrional de padres españoles; igualmente lo es porque "en él se perfila el sentimiento de nacionalidad". Las obras históricas suyas presentan un historiógrafo criollo de la época, que habla de la acción evangelizadora, de los señoríos indígenas, de la vida conventual, de la milagrería, de las acciones militares, de los sucesos cotidianos, de la lucha colonialista, de la ciencia. Deliberadamente eleva su patria a tema de reflexión. El reforzamiento de la personalidad criolla intensifica el nacionalismo. El criollo, dice la autora, "busca su definición con apremio". Por eso exhibe un interés altamente nacionalista. Lo dirige la persuasión de que la patria es nueva, diferente, con características propias, digna y comparable a otras naciones.

Tal significado arroja la concepción de América. Comienza por manifestar el error de creerse el americano inferior en ciencia al europeo. 
De sí mismo refiere la seguridad de que los hombres doctos han estimado sus observaciones, con especialidad las del cometa del año 1681, que dio motivo a la Libra astronómica y filosófica, "por haber igualado en su precisión a las más exactas y primorosas de la Europa". Luego afirma la igualdad y aun la superioridad precisamente en ciencia moderna. La obra filosófica suya nace como una respuesta al científico europen todavía atrasado en su idea de los cometas. El proceso lo termina comparando la cultura americana y la europea. Las armas americanas son superiores y superiores son las actitudes morales y religiosas. América se distingue igualmente por su pasado indígena, al que Sigüenza resalta para integrarlo a la tradición americana. Con todo ello se completa el nacionalismo más agudo y significativo del siglo XviI. "El vehemente deseo que de elogiar a los míos me pulsa siempre", al cual se refiere en el Triunpho Parthénico, lo sacia al saber que ya tiene una nación peculiar con un significado propio. Naturalmente el nacionalismo contribuye a la formación de la conciencia nacional y del sentimiento de autonomí, temas que sólo cabe mencionar aquí.

Precisa anudar significaciones. La modernidad es operativa e impulsa una grandeza nacional asentada en un ser patrio que adquiere su singularidad de la herencia indígena, en un criollismo que se fortalece con las virtudes del mundo hispánico, en la persuasión de ser los novohispanos superiores y de tener una nación diferente. A la decadencia escolástica sigue la grandeza producida por la modernidad. La modernidad descrita, lejos de ser una simple teoría, funciona como una palanca que mueve las aspiraciones del criollo hacia el nacionalismo. Por idéntica razón la modernidad potencia lo mexicano y lo eleva a máxima conciencia de sí. El mexicano no sólo sigue el saber europeo, sino aun lo supera subjetivamente en acciones políticas, religiosas y académicas. Se advierte ya hasta dónde es moderno Sigüenza. En su modernidad estriba su significación histórica. Tal vez las generaciones, de. su época a la nuestra, le han dado el nombre de sabio precisamente por sus ideas modernas.

Con Carlos de Sigüenza y Góngora, sin duda alguna, la Nueva España está a la altura de los tiempos: inicia el proceso de modernidad que acabará de cumplirse en la segunda mitad del siglo xvirr con Alegre y Clavijero, Alzate y Bartolache, Gamarra, Velázquez de León, Antonio de León y Gama, Mociño. No basta, con todo, señalar el logro de los tiempos modernos, pues se corre el peligro de juzgar una época en función de otra, un autor por el desarrollo de otro. En rigor no es posible preferir la construcción mental a la realidad. No podemos hacer a Sor Juana más moderna que la matemática certidumbre de Sigüenza. Y lo mismo habrá que decir si es más moderno Clavijero cuando define la verdadera filosofía con la física útil, o lo es Alzate, el demoledor de 
errores, para el cual el criterio de verdad reside en lo útil. Entre los diversos tipos de eclecticismos novohispanos del siglo xviI, ¿̇se escogerá el de Gamarra? Resulta manifiesto que en la historia de las ideas no puede medirse una época por otra. Este principio nos obliga a pensar lo mođerno de Sigüenza históricamente. El erudito mexicano del xvir no sufre la comparación con Clavijero, o con Alzate, o con Gamarra. Comparado con ellos está a medio camino de los tiempos modernos; visto en su historia, expresa unos tiempos modernos como podian ser $y$ como fueron en la segunda mitad del siglo xvir. Lo singular que ofrece el sabio mexicano recibe el nombre de modernidad, la modernidad particular de una época.

La modernidad no proviene sólo de la Libra astronómica y filosófica, o del Manifiesto filosófico contra los cometas. Conviene decir de manera expresa que don Carlos traslada sus inquietudes de la ciencia a la historia o a la literatura. Ni siquiera resulta lícito del todo decir solamente que hay una vinculación de la historia con la ciencia, como apunta la autora Laura Benítez. La misma obra, La idea de historia en Carlos de Sigüenza y Góngora, da suficiente pie para reconocer que el espíritu moderno de la ciencia existe en la historia. En aquélla de un modo, al modo científico; en ésta de otro modo, al modo histórico. La modernidad se encuentra íntegra en ambas, aunque las manifestaciones sean adversas. La modernidad toma la condición de un todo, mediante el cual la cultura completa de don Carlos adquiere un sentido. Y como tal no puede ser establecida a priori, antes de esclarecer los hechos, modernos y antiguos, que la estructuran. Sus notas y características, por lo tanto, se captan a posteriori, pues son el resultado de la evaluación de los hechos.

Significa bastante decir que Sigüenza es un autor moderno "en la medida en que participa de las nuevas perspectivas a que da lugar la crisis del Renacimiento". También trae luces la tesis de que el moderno, por ser moderno, rechaza el pasado, produciendo con ello la crisis de la cultura tradicional y suscitando innumerables contradicciones. Tales juicios de la autora describen, sin duda, la modernidad. Son, sin embargo, el resultado de la labor interpretativa que compete al historiador. Este formula, irremediablemente, desde sí mismo y su tiempo, sentencias. Por lo cual puede escapársele el acontecer mismo. De hecho el erudito mexicano no tiene conciencia de una crisis cultural, ni advierte contradicciones en su obra. Claro que consideraba su ciencia moderna opuesta a la escolástica dominante, pero no le sorprendía el saber de su tiempo, porque era una creación natural del hombre y la verdad avanzaba. No se manifiesta en momento alguno preocupado por sus ideas modernas; simplemente vive persuadido de que pertenece a 
los tiempos modernos y de que participa en ellos con dignidad de criollo y por derecho adquirido en su condición de hombre.

Históricamente esta modernidad, lo mismo que aquélla de los autores mexicanos del siglo xvir, es original, por constituirla un conjunto de doctrinas, de actitudes, de sentimientos, de convicciones no repetidas y singulares. En las tesis de Sigüenza se realizan perfectamente las cualidades de lo histórico: ser a la vez únicas, irrepetibles, singulares. Así entendida, su modernidad debe ser considerada como una síntesis personal de cultura, ya sea histórica, ya sea científica o filosófica. En última instancia la modernidad del erudito barroco es una síntesis de conocimientos, donde concilia lo antiguo y lo moderno, la ciencia y la religión, el apego a la tradición y la libertad de pensar, la autoridad y la razón. Se trata realmente de una unión. de lo viejo y lo nuevo. Vista desde fuera, aparecen las contradicciones, la crisis, el rechazo. Desde dentro, surge la modernidad histórica, sostenida por el sabio barroco como resultante de sus conocimientos y de sus actitudes.

A esta síntesis, vista interpretativamente, desde fuera, se le ha llamado eclecticismo. Adquiere características propias en nuestro medio, según ha visto el maestro José Gaos. Se trata de una situación oriunda de una comunidad; se presenta cuando hay situaciones históricas y vitales de conflicto "entre instancias de la cultura que no parece posible resolver sino 'eligiendo' de la una y la otra". El término, quizá por ser interpretativo, nos da inteligibilidad del caso Sigüenza. También arroja luces sobre su valor histórico. En efecto, tal eclecticismo no es creador a la manera de las grandes figuras del pensamiento, pero, en cambio, es salvador de situaciones históricas críticas. Y ciertamente Sigüenza merece el título de salvador por cuanto renueva la cultura de su país, en el cual logra introducir la ciencia moderna, y por cuanto piensa a su país con ese bagaje científico. La salvación de su propio y cercano mundo implica, con todo, a nivel de la historia patria y del pensamiento hispanoamericano, una modernidad original y fecunda, como se ha querido probar en las líneas anteriores.

De esta manera el libro de Laura Benítez Grobet, La idea de historia en don Carlos de Sigïenza y Góngora, proporciona elementos bastantes para conocer la categoría de modernidad, tal como surge de la segunda mitad del siglo xvir, esa época tan decisiva dentro de la filosofía de la historia mexicana, precisamente por expresar ya los tiempos modernos. Se advierte que la categoría de modernidad no sólo descubre las notas y los alcances del pensamiento de Sigüenza y Góngora, sino también ella misma adquiere su cabal sentido al ser obtenida inductivamente en cada caso concreto. No hay una modernidad genérica; hay una categoría circunscrita a hechos individuales, irrepetibles. Por eso Sigüenza es un autor moderno y no de transición de los días tradicionales a los nuevos días. 